\title{
Narratives about a stigma: attributing meaning to the early loss of deciduous teeth on children's caregivers
}

\section{Fernando Valentim BITENCOURT(a) Jonas Almeida RODRIGUES(b) Ramona Fernanda Ceriotti TOASSI(c)}

(a) Universidade Federal do Rio Grande do Sul - UFRGS, School of Dentistry, PostGraduate Program in Dentistry, Porto Alegre, RS, Brazil.

(b) Universidade Federal do Rio Grande do Sul - UFRGS, School of Dentistry, Department of Surgery and Orthopedics, Porto Alegre, RS, Brazil.

(c) Universidade Federal do Rio Grande do Sul - UFRGS, School of Dentistry, Department of Preventive and Social Dentistry, Porto Alegre, RS, Brazil.

Declaration of Interests: The authors certify that they have no commercial or associative interest that represents a conflict of interest in connection with the manuscript.

Corresponding Author:

Fernando Valentim Bitencourt

E-mail: fernando.bitencourtxd@gmail.com

https://doi.org/10.1590/1807-3107bor-2021.vol35.0044

Submitted: April 4, 2020

Accepted for publication: September 1, 2020

Last revision: December 16, 2020
Abstract: Qualitative approach about the implications that occur succeeding the premature loss teeth is still insufficient. This study aimed to understand the experience of early loss of deciduous teeth in children's lives, from the perspective of their caregivers. Qualitative case study included 52 caregivers of children from an outpatient service of a public university in the south of Brazil. Early loss of deciduous teeth to trauma or caries was identified through analysis of health records, and afterwards, semi-structured interviews were performed. Textual material was interpreted through the content analysis proposed by Bardin, supported by the ATLAS.ti software. The theoretical perspective of stigma was guided according to the principles of the phenomenology of Maurice Merleau-Ponty, centred on the experience of early loss of deciduous teeth as a historic-cultural expression of a social group. According to caregivers, premature loss of deciduous teeth due to trauma or decay brings functional limitations with chewing and speaking, and impairments related to social interaction with other children. The repercussions of missing teeth were not limited to the child's image, but also brought changes in families' daily lives. However, when early tooth loss was due to extraction because of pain and suffering, caregivers perceived the loss as 'commonplace' in children's lives. The understanding of how children see themselves without teeth in their social world for their caregivers, which also includes their family and friends, determines how much experiencing tooth loss affects their lives. Besides, caregivers' perceptions related to early loss of deciduous teeth should be included in strategies of oral health promotion programs.

Keywords: Child Health; Oral Health; Tooth Loss; Qualitative Research; Social Stigma.

\section{Introduction}

Cultural norms and practices influence a wide variety of social factors, such as values, beliefs, and customs. ${ }^{1}$ In this context, parents or other caregivers are considered the main source of knowledge about the oral health practices of children, influencing health status in the long term. ${ }^{2}$ 
Tooth loss has several social and physical consequences. Some studies have described these experiences on adults. ${ }^{3,4}$ For children, studies mainly describe the physical aspect caused by the early loss of primary teeth that include malocclusion, either retardation or acceleration of permanent tooth eruption, ${ }^{5}$ and impaired pronunciation and chewing functionality, ${ }^{6,7}$ yet few studies assess the social dimensions. Furthermore, no study to date has assessed the effects of these issues in children's lives, from the perspective of their caregivers, employing a qualitative research approach through a phenomenological lens. ${ }^{8}$

Early loss of deciduous teeth is characterised by the absence of a deciduous teeth before the process of natural exfoliation. ${ }^{9}$ Such absence may occur for two main reasons: dental decay that leads to extraction, and dental trauma. ${ }^{10,11}$ Children with experiences of tooth trauma or decay present impaired oral health and quality of life. ${ }^{12}$ Their families may also be affected by teeth loss due to decay. Parents tend to feel guiltier as the child's disease becomes more severe; the probability of guilt increases when they believe their child has a dental problem that could have been avoided. ${ }^{13}$ The lives of both children and their families may change due to psychosocial effects of this early loss. Families may have their own quality of life impacted by changes in their child's quality of life. ${ }^{14}$

A qualitative approach to studying the early loss of deciduous teeth has several implications for policy, public health and health professionals. The phenomenological world view seeks to understand and interpret experiences, located in a certain context, surrounded by the things of the world, among the many that we face. ${ }^{8,15}$ Understanding the meaning of the early loss of deciduous teeth in children's lives, from the perspective of their caregivers, allows oral health teams to learn further about children's condition and adaptation to it. ${ }^{16}$ Considering that caregivers are primarily responsible for children's oral health maintenance, assessing their perception of the experiences of early tooth loss is important. Therefore, this study aimed to understand the experience of early loss of deciduous teeth in children's lives, from the perspective of their caregivers.

\section{Methodology}

This was a qualitative case study, ${ }^{17}$ and phenomenological nature ${ }^{8,15}$ of parents of children who attended the Pediatric Clinic of the Dental School of the Federal University of Rio Grande do Sul (UFRGS) and follows COREQ consolidated criteria for improving the quality of reports of qualitative research. ${ }^{18}$ The study was approved by the Local Ethics Committee in Research (1.652.310). All participants read and signed an informed consent before entering the study and were informed that they could withdraw at any time from the study without detriment to the caregiver or their child in dental care.

\section{Recruitment strategy}

Children with early loss of deciduous teeth were recruited through analysis of oral health records. Teeth loss could have been due to dentoalveolar trauma, extensive decay leading to extractions, and/or other specific situations resulting in early loss of a deciduous tooth.

Health record analysis was conducted by a single researcher, ensuring the confidentiality and non-identification of patient information. Early loss was defined as occurring before the complete formation of the crown and when root formation had been already initiated, i.e., up to Nolla 6 stage. ${ }^{19}$ Records which included radiography, evaluation of early teeth loss was complemented by analysis of the stage of the successor permanent tooth eruption. Children whose clinical reports showed an absence of one or more deciduous teeth, in any of the arches, with a gap in time of at least one year before eruption of the successor permanent tooth were selected. ${ }^{20}$ The inclusion and exclusion criteria are presented in Figure. Were excluded oral health records of children whose early tooth loss was not early; oral health records that presented inconsistent information, difficult to understand, as well as those in which the dental clinical examination was not complete; oral health records in which there was only the report of attendance by the university's urgency / emergency service; oral health records of children who were away from care due to hospitalization. 
After selection of eligible participants, caregivers were then invited to be interviewed in a reserved room at the university.

\section{Interviews with caregivers and data analysis}

To understand the experiences of early loss of deciduous teeth, we used field notes regarding perceptions, feelings and interactions with participants (during and after each interview) and individual semi-structured interviews with the children's caregivers. The script with guiding themes was previously tested with 5 participants, and these data were included in the data analysis. In brief, the questions that guided were "What is your memory of the situation that caused the child to lose the 'baby' tooth before the time considered normal? The absence of this 'milk tooth' affected the life of the child? Have you stopped doing any activities because of this? Did it have any financial impact?
How does the child feel about it? How do you and other family members feel?". An interview guide was formulated through a phenomenological lens, looking for the meanings attributed to the experience from the caregivers' perspectives. ${ }^{21,22}$ Phenomenology refers to the study of human phenomena in social contexts, and the perspectives of the people who experience them. ${ }^{23}$

Each interview lasted around 40 minutes and were performed by a single researcher (F.V.B.), with experience in qualitative research, without any involvement or knowledge prior with the caregivers. Then, the interviews were audiotaped and then transcribed completely in detail to capture speech characteristics, such as emphasis, speed, tone of voice, time and pauses, crucial for data interpretation. As the interviews were being conducted, textual transcription was done after each recording by a single researcher (F.V.B.)

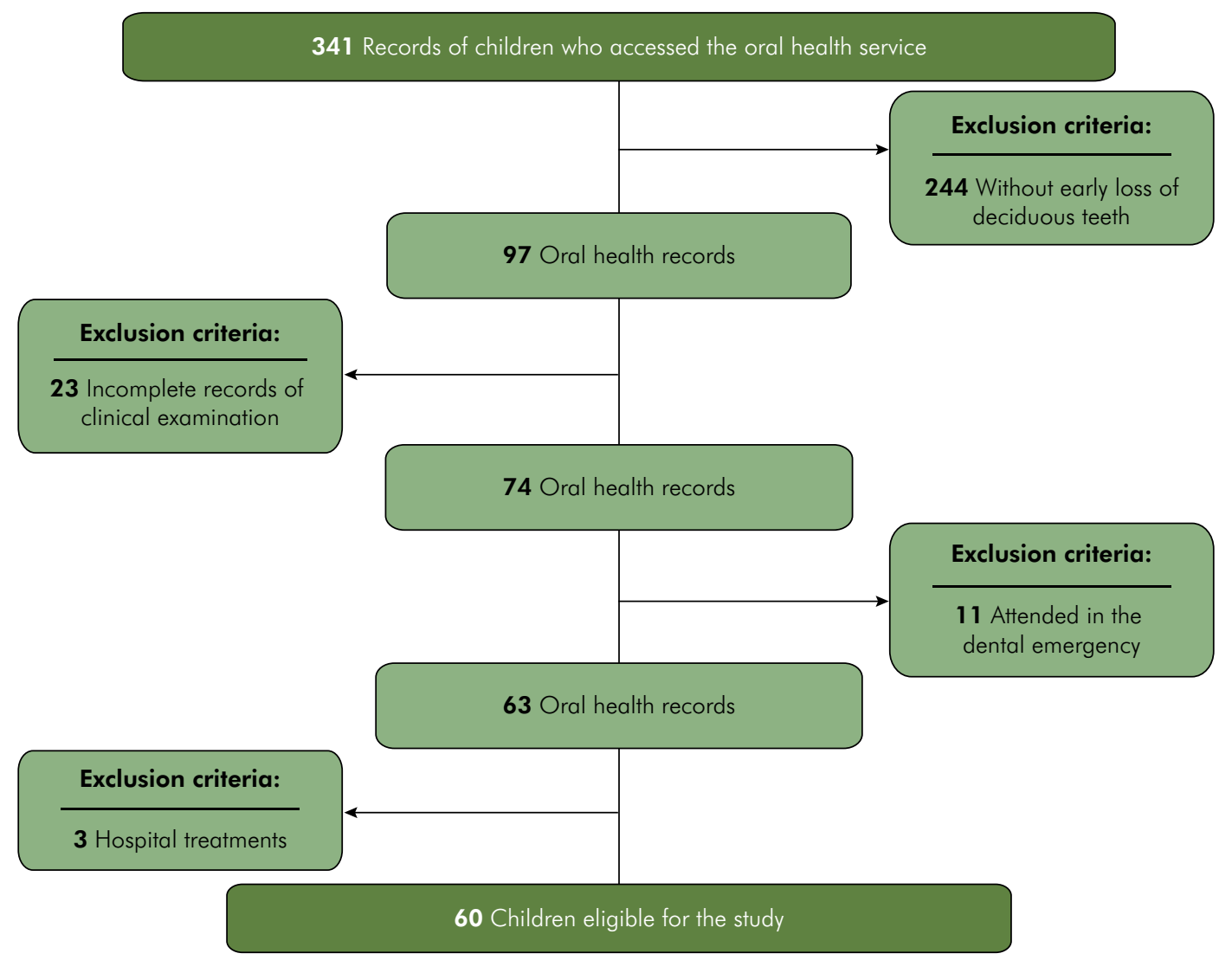

Figure. Criteria for selecting the sample of children who accessed the oral health service of the Faculty of Dentistry through the analysis of oral health records. 
previously trained and instructed by the senior researcher (R.F.C.T.). In order to minimize possible bias in data transcription, for every 5 interviews carried out, one transcribed interview was chosen randomly to be heard and read simultaneously by the researchers. Sampling was intentional and the number of participants was defined by theoretical saturation criteria. ${ }^{24}$ When we observed repetition of topics in the interviews, given the density of the material collected, we decided to end data collection in the 52nd person interviewed.

All interviews were read and reread to guarantee familiarity with the data, which was imported to the ATLAS.ti visual qualitative data analysis software and interpreted through Bardin's content analysis by two researchers with experience in Social and Human Sciences (Public Health) in way independent (F.V.B. and R.F.C.T.). ${ }^{22} \mathrm{~A}$ third researcher (J.A.R.) with a solid scientific background in Pediatric Dentistry contributed to the data analysis and in cases where there was disagreement between the researchers during the data analysis process, this researcher resolved the impasse. The reflexivity among researchers from different areas was about recognizing that as researchers we are part of the social world we study. ${ }^{21}$ This process determined the involvement of the authors in all stages of this research in the form of dialogue, perspectives and challenging assumptions.

In data analyses, the content analysis considered the content related to the early loss experiences, producing 'units of meaning' - categories - following four steps: pre-analysis, material exploration, treatment, and interpretation of the results. ${ }^{22}$ In brief, a full reading of empirical data was performed. At this stage, all interview files were considered useful in understanding the studied phenomenon. The textual material produced by the transcription of the interviews was organized and categorized with the support of ATLAS.ti software. A random number was automatically assigned to each document, based on the code in each interview without revealing their identity (i.e., interview 3, interview 15). The next step basically consisted of transforming raw text data into coding based on the research objective and the theoretical framework.
Finally, the analysis categories were processed and explored to form meaningful and valid conceptual links allowing the researcher to establish the results found. ${ }^{23}$ The interviewees' experiences are presented in the results by narratives, as a structure of meanings of life in a close connection with social and cultural aspects. ${ }^{25}$

The reflexivity among researchers from different areas enriched the analytical attention on the subjectivity of this research, determining the lens through which the researchers looked to understand the participants' experiences and social meanings. In this sense, the results found below are consequences of the dialogue between the different perspectives and challenging assumptions of the researchers, associated to the theoretical framework adopted around the loss of deciduous teeth as a cultural expression of a social group ${ }^{8,15,25,26,27,28}$ as well as other theoretical perspectives that guided in the analysis of the first ${ }^{1,2,3,7,11,12,27,29,30}$ and the second ${ }^{13,14,16,21,28,31,32,33,34,35}$ categories.

In this study, a social group is not considered to be a simple aggregate of individuals, but rather exhibits some degree of social relationship in society, for example, shared characteristics (barriers to access the public oral health service and experiences of caregivers of children with experience of early loss of deciduous teeth due to caries or trauma). Such experiences share common interests, values, representations and bonds. ${ }^{36}$

\section{Results}

No individual refused to participate or dropped out of the study, reaching a total of 52 interviews with caregivers of children under treatment. Table summarises the characteristics of participants.

\section{Meaning of early loss of primary teeth in children's lives}

The experience of early loss of deciduous teeth in children had different meanings from the perception of their caregivers. They understood the loss as a phenomenon causing impairments in children's daily lives, related to limitations in speech and, especially, in chewing. 
Table. Description of participants.

\begin{tabular}{|c|c|}
\hline Characteristics of caregivers and children & $\mathrm{n}(\%)$ \\
\hline \multicolumn{2}{|l|}{ Caregiver gender } \\
\hline Female & $42(80.8)$ \\
\hline Male & $10(19.2)$ \\
\hline \multicolumn{2}{|l|}{ Caregiver relationship to child } \\
\hline Mother & $35(67.3)$ \\
\hline Father & $10(19.2)$ \\
\hline Aunt & $2(3.9)$ \\
\hline Grandmother & $5(9.6)$ \\
\hline \multicolumn{2}{|l|}{ Age of caregiver (years) } \\
\hline $20-29$ & $12(23.1)$ \\
\hline $30-49$ & $33(63.5)$ \\
\hline 50 or over & $7(13.4)$ \\
\hline \multicolumn{2}{|l|}{ Child gender } \\
\hline Female & $19(36.5)$ \\
\hline Male & $33(63.5)$ \\
\hline \multicolumn{2}{|l|}{ Child age (years) } \\
\hline Up to 4 & $5(9.6)$ \\
\hline $5-7$ & $23(44.2)$ \\
\hline $8-10$ & $22(42.3)$ \\
\hline $11-12$ & $2(3.9)$ \\
\hline \multicolumn{2}{|l|}{ Cause of teeth loss } \\
\hline Caries & $44(84.6)$ \\
\hline Dental trauma & $8(15.4)$ \\
\hline \multicolumn{2}{|l|}{ Number of teeth loss } \\
\hline $1-2$ & $28(53.9)$ \\
\hline $3-4$ & $18(34.6)$ \\
\hline 5 or more & $6(11.5)$ \\
\hline Total & $52(100.0)$ \\
\hline
\end{tabular}

She became a little silly to speak, you know? It is because they took off her teeth, so there is a difference in her speech, right?... She worries with eating. Last week she already said, 'Now how am I gonna eat?'. (Interview 52)

In chewing he says it lacks teeth, it bothers a little where there is no milk teeth. So, this affected his life. (Interview 44)

The repercussions of missing teeth reflected on the child's self-image, affecting social aspects of their relationships with others. This was evidenced in the narratives where caregivers noticed 'jokes' and 'nicknames' related to the absence of anterior teeth, which annoyed the children. The interview below shows that prejudice against the absence of anterior teeth and stigmatization are present in the daily lives of children: In front of our gate, some boys said, 'What's up, little window?'
These jokes annoy... but it is because friends say, 'What's up,
little door*?'. (Interview 3 )

He thought he was going to stay toothless. How can I explain a child's mind to you? It is like I would feel, man, if I lost a tooth, I think I would be ashamed... He was embarrassed, didn't smile much. (Interview 10)

To smile, I see that he stays in front of the mirror, looking... and I say, 'it is not supposed to be this way, this is not good for you'. (Interview 3)

Thus, it is possible to observe through the experiences told by the caregivers how the missing tooth is seen in the children's world. It is observed through the speech that the child's self-image without a tooth in the front is bad and ugly "little window", that is, a stigma and that for this reason, they are different from other children, resulting in greater difficulties to be accepted by the group. Social stigma is defined as the situation of the individual who is disabled for full social acceptance. ${ }^{27}$ The tooth loss generated negative feelings in children, such as shame about the condition of their mouths. These reports describe that such shame manifested as limitation of smiling.

In other situations, early tooth loss during a dentist appointment (extractions due to decay), following a condition that involved the child's previous experiences such as 'pain', 'suffering', 'black teeth in their mouth', or 'teeth which are bad for chewing', had a different meaning. While remembering their children with decayed teeth that brought pain and suffering, caregivers dealt with this loss as 'commonplace', expected, and a relief, without blaming or stigmatising the child. They believed that at some point children

\footnotetext{
* Brazilian nicknames for children missing their front teeth.
} 
'lose their baby teeth' so that the permanent ones can come. In this context, the child's life did not seem to be so affected by tooth loss and the differences became 'normal'.

I was very sad, right, at the same time I was shocked to take out her four teeth, but then... I got it... I even got used to it, it's normal so much so that the others start to grow. (Interview 9)

He's my son, I felt sorry for doing anaesthesia and pulling everything out [teeth]. But what am I going to do? He had to pull it out, it was spoiled, expected [...]. My husband says, oh poor thing, we had to give him confidence, that the tooth was 'milk', that another one will be born normal. It is sad but on the other hand it was good, because now he is well and will have to be careful if he won't have to keep extracting. (Interview 12)

For him it is commonplace, it was well explained to him that another tooth will come there, there will be another tooth there, this is for the moment, and also, kids these age only think about aesthetics when their mother puts it in their heads. We have to remove stigmas, 'Men doesn't wear pink, men wears, pink is a colour'. We are taking all prejudices away from him, for him everything is normal, being different is normal. (Interview 15)

I see him missing his little tooth, we think... 'Toothless kid, so early, is ugly', but at the same time we see him having fun with this new situation, it was not told that it was his fault, it is said to be a new situation and that new is cool. (Interview 25)

\section{Early loss of deciduous teeth affecting children's families}

More than affecting children's lives, early tooth loss also brought changes in families' daily lives.

This event awoke me because it is very important to take care of oral hygiene. Now, my son is bringing his kids to the dentist too, because what happened was a great example for them too. (Interview 4)

I can't wait for the permanent tooth to come in... so that he keeps the tooth and has all the care that I did not. (Interview 3)

Caregivers recognise the importance of oral care and take responsibility. They may even blame themselves for the loss of these teeth, both in situations where the tooth loss happened due to decay and those due to trauma.

It was a shock to me, he losing his tooth so young... I say to my husband that it was because we relaxed too much, because we are responsible for our kids, for their eating education... it is our fault and not his, we have to keep and care, and not let the kid decide. (Interview 8)

I feel very responsible and guilty for the fact that he lost his tooth, because it was a silly fall and which maybe if it had been inside our house, if he wasn't running outside he wouldn't have been through all this process, specially the pain. (Interview 6)

This feeling of responsibility and guilt led caregivers to seek dental treatment to see their children healthy again. Thus, having their teeth in their mouth was associated with having a 'healthy body', capable of digesting food, as observed:

I feel bad, because I am responsible for him. That is why I looked for help, to see my son healthy and well. He depends on his teeth to digest food and for his body to be healthy. (Interview 8)

I see that for him the lack caused discomfort, because he has to have healthy teeth for the body to be well, to eat well and to digest food well. (Interview 18)

I saw during today's interview that the child's mother had a feeling of guilt for her son's oral health situation, she filled her eyes with tears while talking to me. But now she [mother] is feeling better about seeing that her son is chewing and speaking better due to care for oral health. (Researcher's field notes)

\section{Discussion}

In this study, caregivers of children who lost their teeth before the expected period of natural exfoliation reported how they perceived the loss process by the children without teeth in their social world. Caregivers understood the tooth loss as a phenomenon that causes damage in the daily lives of children when this loss due to caries or trauma leads to limitations in speech and especially in chewing. Moreover, the repercussions of missing teeth reflected on the child's self-image, affecting social aspects of their 
relationships with others. This experience includes aspects related to family and friends, and to what extent this tooth loss affected their lives. To the best our knowledge, there are no in-depth qualitative studies that have investigated the meanings of early loss of deciduous teeth in children's lives, from the perspective of their caregivers.

Researches have used quantitative structured questionnaires to learn about and evaluate oral health in children, associating it with quality of life. ${ }^{35}$ Nevertheless, do not provide insight into the life-worlds of children qualitatively and analysis of un(der)explored facets of the experience of early loss of deciduous teeth from the perspective of phenomenology. Given the need for analysis that allows understanding of human behaviours and beliefs, this study shows the meaning of the experience of early tooth loss in the lives of children and their families, from the perspective of caregivers. The child, due to the characteristics of their stage of development, depends on the care and support of the family. Although the central focus was on the teeth loss of the child, understanding took place through the figure of the caregiver, since they make the day-to-day decisions regarding the child's wellbeing. As they usually live in the same family and social context, interviewing the caregiver allowed in-depth understanding of the child's experiences, allowing clarification, recognition and description of the phenomenon of early teeth loss. ${ }^{31}$ It dealt phenomenologically with the meaning of experience and 'being in the world'. We do not exist separated from the world of our experience; we are part of it. ${ }^{21}$ Early loss of deciduous teeth was perceived by caregivers as a problem for children when it caused limitations in chewing, speaking, image (aesthetics) and social living with other children. The same negative impacts have been reported in the literature, focusing on functional aspects related to chewing and swallowing and correct pronunciation, 7,32 as well as on psychological aspects such as image and self-esteem, ${ }^{33}$ and on social aspects relating to interaction and communication with other children. ${ }^{34}$

We understand the body as the axis of a person's relationship with the world, which allows them to see, hear, taste, feel, touch, and place meanings on this world around them. ${ }^{26} \mathrm{~A}$ child missing tooth due to dental caries or trauma brings to their body a certain mark that may stigmatise them ('toothless', 'little door', 'little window'). This absence can become a subtle reason for a negative valuation of the child, a 'difference' that may negatively affect their selfesteem and challenge their social relations and the way this 'deficient body' lives in the social group.

Although it is expected that children 'naturally' lose their teeth as part of their development, when they lose their teeth earlier, they become 'different', with a body branded with a potentially negative value that could be a disadvantage compared to children with teeth. ${ }^{12}$ This stigma can inhibit full social acceptance. ${ }^{27}$ The more visible the brand, the less possible it is for the child to hide it in their interpersonal relations and social network; once identified, what was merely different becomes a 'branded body', an impaired image that society does not take as standard. ${ }^{29}$

However, the early loss of deciduous teeth may also be considered an expected condition in children's lives, when it occurs due to a previous situation of 'pain' or 'suffering', turning tooth loss into a relief. In this case, the consequences of the loss are minimised by caregivers, considering deciduous dentition less important and attributing more value to permanent dentition. These are perceptions that reinforce the acceptance of tooth loss in the deciduous dentition as 'commonplace. ${ }^{37}$

Most caregivers interviewed were mothers of male children aged between 5 and 12 years old, which corroborates with studies in the field of pediatric dentistry and public health in relation to caregivers and access to dental services. ${ }^{38,39}$ Caregivers presented different positions in relation to early teeth loss, which in turn influenced the way children saw themselves without teeth. Even within great socio-cultural diversity, families generally have a great impact on the development of children's oral health habits. ${ }^{40}$ Caregivers in this context are the main source of knowledge for children's education and health habits. ${ }^{41}$ They play a fundamental role in the determination in oral health, positively or negatively influencing the adoption of attitudes and behaviors. ${ }^{42}$ Therefore, caregivers may positively influence the child's perception of their tooth loss, so that damages are minimised.$^{28}$ Through family bonds, the stigmatised child may find the necessary support 
for their differences, in the context of similarities. The child can relativise the difference and add meaning to their social identity. ${ }^{1}$

As well as affecting these children's lives, tooth loss also showed implications in families' daily lives. Children are not independent beings, and families comprise the network of individuals who deeply support and affect their quality of life..$^{43}$ Evidence in the literature demonstrates the impact of tooth loss on the whole family, which can undergo an emotional and financial upheaval to solve the dental situation. ${ }^{5}$

Caregivers often blame themselves for children's tooth loss due to either decay or trauma. This guilt increases when they believe that their child's dental problem could have been avoided. ${ }^{41}$ Hence, early tooth loss may translate into limitations in the child's daily activities, but also into psychosocial impacts and guilt affecting the family. ${ }^{4}$

Another aspect to be considered is the association between 'having teeth' and 'having a healthy body'. Corporal image involves all the forms by which the individual lives, not mere perception - the child notices and defines their body, in physical, social, cognitive and emotional aspects. ${ }^{26}$ When oral problems are visible while speaking and smiling, the child's attitude worsens in relation to themselves and to others. ${ }^{30}$ The caregivers in this study particularly described having healthy teeth as related to having a healthy body, from which it can be inferred that the mouth is not considered separately from the body.

Some strengths and weaknesses should be highlighted in the present study. As the strengths, this article includes the efforts that were made in an attempt to understand and analyse the social phenomenon studied from the researchers' epistemological positions of the Public Health and Paediatric Dentistry. This articulation between the areas qualifies the reflexivity and scope of this study, as well as the methodological rigidity, providing a more in-depth evaluation of caregivers' reports. As limitation of the study, notably the interviews were conducted with caregivers of children who were involved with a university dental care service. In this context, it was not possible to assess other experiences of teeth loss, such as in children who did not receive dental treatment. Additionally, emotions can be influenced by memory bias. Caregivers can better remember the experiences in which early tooth loss impacted the child's life, while other less affected experiences tend to forget their past history more easily.

\section{Conclusions}

This qualitative research, formulated through a phenomenological lens, presents an important contribution to the advancement of scientific evidence about the experiences of early tooth loss in children from the perspective of their caregivers, and present implications for public health and for health professionals. Losing primary teeth early due to caries or trauma, in the perception of caregivers, brought to the child functional limitations associated with chewing and speech, in addition to impairments related to physical appearance and social interaction with other children. Also, the interviews showed the stigma as a cultural expression in children. However, when this loss was motivated by the extraction of decayed teeth that caused pain and suffering, caregivers perceived the loss as a necessary and expected fact in the lives of children. Finally, findings suggest new studies with phenomenological nature to listen to children's experiences.

\section{Acknowlegments}

This study was financed in part by the FAPERGS Scientific Initiation Scholarships (PROBIC).

\section{References}

1. Hilton IV, Stephen S, Barker JC, Weintraub JA. Cultural factors and children's oral health care: a qualitative study of carers of young children. Community Dent Oral Epidemiol. 2007 Dec;35(6):429-38. https://doi.org/10.1111/j.1600-0528.2006.00356.x

2. Al-Shalan TA. Factors affecting Saudi parents' perception of their children's first dental visit. J Contemp Dent Pract. 2003 Nov;4(4):54-66. https://doi.org/10.5005/jcdp-4-4-54 
3. Ortíz-Barrios LB, Granados-García V, Cruz-Hervert P, Moreno-Tamayo K, Heredia-Ponce E, Sánchez-García S. The impact of poor oral health on the oral health-related quality of life $(\mathrm{OHRQ}$ oL) in older adults: the oral health status through a latent class analysis. BMC Oral Health. 2019 Jul;19(1):141. https://doi.org/10.1186/s12903-019-0840-3

4. Schierz O, Baba K, Fueki K. Functional oral health-related quality of life impact: A systematic review in populations with tooth loss. J Oral Rehabil. 2020 Apr;joor.12984. https://doi.org/10.1111/joor.12984

5. Jayachandar D, Gurunathan D, Jeevanandan G. Prevalence of early loss of primary molars among children aged 5-10 years in Chennai: a cross-sectional study. J Indian Soc Pedod Prev Dent. 2019 Apr-Jun;37(2):115-9. https://doi.org/10.4103/JISPPD.JISPPD_22_19

6. Vulićević Z, Beloica M, Kosanović D, Radović I, Juloski J, Ivanović D. Prosthetics in paediatric dentistry. Balkan J Dent Med. 2017;21 (2):78-82. https://doi.org/10.1515/bjdm-2017-0012

7. Nadelman P, Bedran N, Magno MB, Masterson D, Castro AC, Maia LC. Premature loss of primary anterior teeth and its consequences to primary dental arch and speech pattern: a systematic review and meta-analysis. Int J Paediatr Dent. 2020 Nov;30(6):687-712. https://doi.org/10.1111/ipd.126448.

8. Merleau-Ponty M. Phenomenology of perception. 4th ed. São Paulo: Martins Fontes; 2011.

9. Brusola JA. Clinical orthodontics. Barcelona: Moiá; 1989.

10. Murshid SA, Al-Labani MA, Aldhorae KA, Rodis OM. Prevalence of prematurely lost primary teeth in 5-10-year-old children in Thamar city, Yemen: a cross-sectional study. J Int Soc Prev Community Dent. 2016 Aug;6(2 Suppl 2):S126-30. https://doi.org/10.4103/2231-0762.189739

11. Holan G, Needleman HL. Premature loss of primary anterior teeth due to trauma-potential short- and long-term sequelae. Dent Traumatol. 2014 Apr;30(2):100-6. https://doi.org/10.1111/edt.12081

12. Scarpelli AC, Paiva SM, Viegas CM, Carvalho AC, Ferreira FM, Pordeus IA. Oral health-related quality of life among Brazilian preschool children. Community Dent Oral Epidemiol. 2013 Aug;41(4):336-44. https://doi.org/10.1111/cdoe.12022

13. Carvalho TS, Abanto J, Pinheiro EC, Lussi A, Bönecker M. Early childhood caries and psychological perceptions on child's oral health increase the feeling of guilt in parents: an epidemiological survey. Int J Paediatr Dent. 2018 Jan;28(1):23-32. https://doi.org/10.1111/ipd.12306

14. Cancio V, Faker K, Bendo CB, Paiva SM, Tostes MA. Individuals with special needs and their families' oral health-related quality of life. Braz Oral Res. 2018 May;32(0):e39. https://doi.org/10.1590/1807-3107bor-2018.vol32.0039

15. Matthews E. The philosophy of Merleau-Ponty. Chesham: Acumen; 2002.

16. Amin MS, Harrison RL, Weinstein P. A qualitative look at parents' experience of their child's dental general anaesthesia. Int J Paediatr Dent. 2006 Sep;16(5):309-19. https://doi.org/10.1111/j.1365-263X.2006.00750.x

17. Baxter P, Jack S. Qualitative case study methodology: study design and implementation for novice researchers. Qual Rep. 2008;13(1):544-59.

18. Tong A, Sainsbury P, Craig J. Consolidated criteria for reporting qualitative research (COREQ): a 32-item checklist for interviews and focus groups. Int J Qual Health Care. 2007 Dec;19(6):349-57. https://doi.org/10.1093/intghc/mzm04219.

19. Sachan K, Sharma VP, Tandon P, Lata Verma S, Srivastav K. To establish the validity of dental age assessment using Nolla's method on comparing with skeletal age assessed by Hand-Wrist radiographs. J Indian Orthod Soc. 2013;47(1):438-42.

20. Araúijo MG. Orthodontics for clinicians: pre-orthodontic program. 4th ed. São Paulo: Santos; 1988.

21. Titchen A, Hobson D. Understanding phenomenology through reverse perspectives. In: Somekh B, Lewin C, editors. Theory and methods in social research. 2nd ed. London: Sage; 2011. p. 170-82.

22. Bardin L. L'snalyse de contenu. Paris: Presses Universitaires de France; 1977.

23. Vaismoradi $M$, Turunen $H$, Bondas T. Content analysis and thematic analysis: implications for conducting a qualitative descriptive study. Nurs Health Sci. 2013 Sep;15(3):398-405. https://doi.org/10.1111/nhs.12048

24. Saunders B, Sim J, Kingstone T, Baker S, Waterfield J, Bartlam B, et al. Saturation in qualitative research: exploring its conceptualization and operationalization. Qual Quant. 2018;52(4):1893-907. https://doi.org/10.1007/s11135-017-0574-8

25. Gergen KJ, Gergen MM. Narrative from and the construction of psychological science. In Sarbin TR, editor. Narrative psychology: the storied nature of conduct. New York: Praeger; 1986. p. 3-21.

26. Le Breton D. Anthropology of the body and modernity. Paris: PUF; 2005.

27. Goffman E. Stigma: notes on the management of spoiled identity. New York: Simon \& Schuster; 1963.

28. Case A, Paxson C. Parental behavior and child health. Health Aff (Millwood). 2002 Mar-Apr;21(2):164-78. https://doi.org/10.1377/hlthaff.21.2.164

29. Chaudoir SR, Fisher JD. The disclosure processes model: understanding disclosure decision making and postdisclosure outcomes among people living with a concealable stigmatized identity. Psychol Bull. 2010 Mar;136(2):236-56. https://doi.org/10.1037/a0018193

30. Abanto J, Paiva SM, Raggio DP, Celiberti P, Aldrigui JM, Bönecker M. The impact of dental caries and trauma in children on family quality of life. Community Dent Oral Epidemiol. 2012 Aug;40(4):323-31. https://doi.org/10.1111/i.1600-0528.2012.00672.x 
Narratives about a stigma: attributing meaning to the early loss of deciduous teeth on children's caregivers

31. Naidu R, Nunn J, Forde M. Oral healthcare of preschool children in Trinidad: a qualitative study of parents and caregivers. BMC Oral Health. 2012 Aug;12(1):27. https://doi.org/10.1186/1472-6831-12-27

32. Vittoba Setty J, Srinivasan I. Knowledge and awareness of primary teeth and their importance among parents in Bengaluru City, India. Int J Clin Pediatr Dent. 2016 Jan-Mar;9(1):56-61. https://doi.org/10.5005/ip-journals-10005-1334

33. Holan G, Rahme MA, Ram D. Parents' attitude toward their children's appearance in the case of esthetic defects of the anterior primary teeth. J Clin Pediatr Dent. 2009;34(2):141-5. https://doi.org/10.17796/icpd.34.2.910037663v7pm6vg

34. Peres KG, Cascaes AM, Leão AT, Côrtes MI, Vettore MV. [Sociodemographic and clinical aspects of quality of life related to oral health in adolescents]. Rev Saude Publica. 2013 Dec;47(3 Suppl 3):19-28. Portuguese. https://doi.org/10.1590/S0034-8910.2013047004361

35. Menegazzo GR, Knorst JK, Emmanuelli B, Mendes FM, Ardenghi DM, Ardenghi TM. Effect of routine dental attendance on child oral health-related quality of life: A cohort study. Int J Paediatr Dent. 2020 Jul;30(4):459-67. https://doi.org/10.1111/ipd.12625

36. Turner JC, Tajfel H, editors. Towards a cognitive redefinition of the social group. Social identity and intergroup relations. Cambridge: Cambridge University Press; 1982.

37. Sami A, Fatima K, Moin H, Bashir R, Ahmed J. Relationship of parental knowledge and attitude with oral health status of children in Karachi East. Br J Med Med Res. 2016;14(9):1-9. https://doi.org/10.9734/BJMMR/2016/24767

38. Kelly SE, Binkley CJ, Neace WP, Gale BS. Barriers to care-seeking for children's oral health among low-income caregivers. Am J Public Health. 2005 Aug;95(8):1345-51. https://doi.org/10.2105/AJPH.2004.045286

39. Comassetto MO, Baumgarten A, Kindlein KA, Hilgert JB, Figueiredo MC, Faustino-Silva DD. Access to oral health in early childhood in the city of Porto Alegre, Brazil. Cien Saude Colet. 2019 Mar;24(3):953-61. Portuguese. https://doi.org/10.1590/1413-81232018243.29082016

40. Hussein AS, Abu-Hassan MI, Schroth RJ, Ghanim AM. Parent's perception on the important of their children's first dental visit: a cross-sectional pilot study in Malaysia. J Oral Res. 2013;1(1):17-25.

41. Bozorgmehr E, Hajizamani A, Mohammadi TM. Oral health behavior of parents as a predictor of oral health status of their children. ISRN Dent. 2013 May;2013(1):741783. https://doi.org/10.1155/2013/741783

42. Castilho AR, Mialhe FL, Barbosa TS, Puppin-Rontani RM. Influence of family environment on children's oral health: a systematic review. J Pediatr (Rio J). 2013 Mar-Apr;89(2):116-23. https://doi.org/10.1016/i.jped.2013.03.014

43. Pal DK. Quality of life assessment in children: a review of conceptual and methodological issues in multidimensional health status measures. Epidemiol Community Health. 1996 Aug;50(4):391-6. https://doi.org/10.1136/jech.50.4.391

44. Alqadi A, O'Connell AC. Parental Perception of children affected by Amelogenesis Imperfecta (AI) and Dentinogenesis Imperfecta (DI): a qualitative study. Dent J (Basel). 2018 Nov;6(4):65. https://doi.org/10.3390/dj6040065 